\title{
Prevalence and Antibiotic Resistance of Salmonella Species Isolated from Chicken Eggs by Standard Bacteriological Method
}

\author{
Kassahun Tessema ${ }^{1}$, Hussen Bedu ${ }^{1 *}$, Mebrat Ejo ${ }^{1}$ and Adem Hiko ${ }^{2}$
}

${ }^{1}$ Department of Biomedical Sciences, Faculty of Veterinary Medicine, University of Gondar, Gondar, Ethiopia

${ }^{2}$ Department of Veterinary Epidemiology, Microbiology and Public Health, College of Veterinary Medicine, Haramaya University, Haramaya, Ethiopia

\begin{abstract}
Salmonella have been found to be the major food borne disease in the world with a serious public health problem. The current study was carried out to detect and to determine the prevalence and antibiotic susceptibility of Salmonella isolated from fresh raw chicken eggs collected at Haramaya University Poultry Farm in Eastern Ethiopia. Among the total 384 chicken eggs, Salmonella spp. was detected from $2.9 \%(11 / 384)$ of egg samples using culture technique and was confirmed by biochemical test, nine Salmonella spp. (2.4\%) were detected from egg shell and two $(0.5 \%)$ from egg contents; predominantly occurred in floor house system. The prevalence of Salmonella in eggs on the bases of chicken breed sources was $2.9 \%, 3.8 \%$ and $2 \%$ for Bovans, Fayoumi and White leg horn, respectively. The prevalence difference did not show statistical significance $(P>0.05)$ between the rate of detecting Salmonella spp. among the egg shell and egg contents, and similarly, non-significant analytical situation was observed in eggs sampled from different chicken breeds. Among the sample sources, egg samples examined from cage and floor house were found Salmonella positive with the prevalence of $2.3 \%$ and $3.3 \%$, respectively. However, there was no statistically significant difference $(P>0.05)$ in the prevalence of Salmonella among the two house systems. All identified isolates were tested for susceptibility to a six commonly used antimicrobials by disk diffusion technique. Out of the 11 isolates tested $8(72.7 \%)$ were resistant to one or more of the tested antimicrobials The most common resistance observed was to tetracycline (72.7\%), ampicillin (72.7\%) and amoxicillin (63.6\%) However, spectinomycin, kanamycin and chloramphenicol were effective against most of the Salmonella isolates.
\end{abstract}

Keywords: Antimicrobials; Eggs; Prevalence; Resistance; Salmonella

\section{Introduction}

Food borne diseases are among the most widespread global public health problems of recent times, and their implication for health and economy is increasingly recognized $[1,2]$. The majority of foodborne outbreaks are caused by Salmonella, Listeria monocytogenes, Escherichia coli, and Campylobacter strains [3]. Among these pathogens, Salmonella are considered the most prevalent foodborne pathogens worldwide $[4,5]$ and has long been recognized as an important zoonotic pathogen of economic significance in animals and humans, predominantly in the developing countries. The important route of transmission of Salmonella organism from animals to man is via food products of animal origin which may be contaminated at the source or during handling [6]. Epidemiological studies show that chicken eggs and meat are two of the most important sources for consumer ingestion and contact of pathogens [7]. Chicken eggs in particular continue to be identified as leading food sources for human Salmonellosis $[5,8]$.

The true incidence of salmonellosis in both humans and animals is difficult to evaluate in developing countries because of the lack of epidemiological surveillance systems $[9,10]$. The ubiquity of Salmonella isolates makes them a persistent contamination hazard to all raw foods [11]. Those of animal origin food products are often implicated in sporadic cases and outbreaks of human salmonellosis $[12,13]$. The distribution of Salmonella serotypes from poultry sources is geographically variable and changes over time, although several serotypes are consistently detected at a high incidence throughout much of the world. Many of the Salmonella serotypes that are most prevalent in humans are also common in poultry [14], suggesting a possible epidemiologic connection between the poultry and human reservoirs of Salmonella. Salmonella infection in chickens has important implication on public health worldwide [15]. Infected chickens can deposit Salmonella in either the yolk or albumen of developing eggs because of the colonization of different regions of the reproductive tract $[16,17]$. It is not yet clear as to which route is most important for Salmonella to contaminate the egg contents, which may be contaminated with Salmonellae by vertical transmission and/or horizontal transmission [18]. Although some authors claim horizontal transmission to be the most important way to contaminate eggs. Barrow and Lovell, most authors claim that vertical transmission is the most important route of egg contamination [19].

In recent years, Salmonella related diseases have been documented by several food related studies conducted in different parts of Ethiopia $[9,20]$. An increased in the resistance of Salmonella to commonly used antimicrobials has been also noted in both public health and veterinary sectors in Ethiopia [20]. Antimicrobial resistance is a natural consequence of infectious agents' adaptation to exposure to antimicrobials used in medicine, food animals, crop production and use of disinfectants in farms and households [21-23]. However, scarcity of surveillance data on the incidences of Salmonella species associated with eggs and its antimicrobial resistance pattern in the poultry farm is a major epidemiological issue. Despite some attempts to study prevalence of Salmonella in Ethiopia, mainly in meat and meat products, the status of the problem in eggs is still very much unknown.

*Corresponding author: Hussen Bedu, Department of Biomedical Sciences Faculty of Veterinary Medicine, University of Gondar, Gondar, Ethiopia, Tel: +251928467384; E-mail: qaroo2016@gmail.com

Received December 06, 2016; Accepted January 20, 2017; Published January 28, 2017

Citation: Tessema K, Bedu H, Ejo M, Hiko A (2017) Prevalence and Antibiotic Resistance of Salmonella Species Isolated from Chicken Eggs by Standard Bacteriological Method. J Vet Sci Technol 8: 421. doi: 10.4172/2157-7579.1000421

Copyright: (c) 2017 Tessema K, et al. This is an open-access article distributed under the terms of the Creative Commons Attribution License, which permits unrestricted use, distribution, and reproduction in any medium, provided the original author and source are credited. 
Very little information is available at this time for Salmonella infection of egg in the country. However, studies made elsewhere indicated that eggs are important sources of Salmonella particularly among those raw consumers [24]. Therefore, this study was aimed to determine the prevalence and distribution of Salmonella spp. on chicken eggs by conventional culture methods and biochemical assays, and also to assess the antimicrobial resistance of the isolates.

\section{Materials and Methods}

\section{Study site}

The study was performed on egg samples collected in Haramaya University Poultry Farm located at Haramaya, Ethiopia. It is approximately 500 kilometres away from Addis Ababa, capital city of Ethiopia. Geographically the study site located at $41^{\circ} 59^{\prime} 58^{\prime \prime}$ North latitude and $90^{\circ} 24^{\prime} 10^{\prime \prime}$ South longitudes. The elevation of this area is about 2000 meters above sea level and its mean annual temperatures ranges from $10^{\circ} \mathrm{C}$ to $18^{\circ} \mathrm{C}$ with the relative humidity of 65 percent respectively. The area receives an annual rain fall of 800 millimetres within a bimodal distribution of the season's pattern peaking in midApril and mid-August of the year. The farm serves mainly for people residing in and the surrounding of East Ethiopia. In the farm, three breeds of chicken (Bovans, Fayoumi and White leg horn) are used for the purpose of egg production and production of day old chicks, which distributed for consumers and farmers of the surroundings and to different regions of the country.

\section{Study design and sampling}

A Cross-sectional study was conducted to determine the prevalence, distribution and antimicrobial susceptibility of Salmonella in chicken eggs from three breeds of layer chickens. Simple random sampling technique was used to collect egg samples from Fayoumi, Bovansand White leg horn breeds of layer chickens in cage and floor housing systems

\section{Egg sample collection}

The sample size was calculated according to Thrusfield, using $95 \%$ confidence interval and 0.05 absolute precision by assuming expected prevalence of $50 \%$ [25]. In total, 384 freshly laid and unwashed chicken eggs were aseptically collected from the farm. The collected egg samples were transported to the laboratory of Veterinary Microbiology, College of Veterinary Medicine, Haramaya University under cold chain and analysed using microbiological protocols for Salmonella isolation and identification. Information on breed, coded ID number of egg and house was registered during collection of egg samples.

\section{Culture method}

Standard cultivation method recommended by the International Organization for Standardization (ISO 6579, 2002) was carried out for isolation and identification of Salmonella [26]. Each chicken eggshell were dipped in sterile peptone broth and swabbed with sterile cotton swabs and then added in Buffered Peptone Water (BPW). In addition, surface sterilized eggs were cracked with a sterile knife and each egg's content was mixed thoroughly and $25 \mathrm{gm}$ of the mixed egg content was inoculated into $225 \mathrm{ml}$ of peptone broth. The mixture then homogenized using a laboratory blender (Stomacher 400R, Seward, England) for 30 seconds. The pre-enriched samples, both from egg shells and egg contents, were incubated for overnight at $37^{\circ} \mathrm{C}$. After the overnight incubation, $1 \mathrm{ml}$ of the pre-enrichment broths was transferred aseptically into a tube containing $10 \mathrm{ml}$ of
Muller-Kauffmann-tetrathionate(MK) broth and incubated at $37^{\circ} \mathrm{C}$ for overnight. Following incubation, a loopful of each enrichment broth culture streaked onto one plate of xylose lysine desoxycholate (XLD) agar and another plate on Salmonella-shigella (SS) agar and incubated at $37^{\circ} \mathrm{C}$ for $24 \mathrm{hr}$. The plates (XLD and SS agars) were examined for the presence of typical Salmonella colonies. Characteristic colony for Salmonella isolates were then transferred onto nutrient agar and incubated aerobically at $37^{\circ} \mathrm{C}$ for overnight.

\section{Biochemical test}

Each identified colonies with typical Salmonella morphology were confirmed biochemically by inoculating into lysine iron agar (LIA), triple sugar iron agar (TSI) slopes, urea agar base, tryptophan broth and methylered-vogesproskaur (MR-VP) medium with confirmation carried out following incubated at $37^{\circ} \mathrm{C}$ for $18-48$ hours, and interpreted with international organization for standardization (ISO 6579, 2002) [26].

\section{Antimicrobial susceptibility test}

Antibiotic sensitivity of the isolates was performed according to agar disc diffusion method on Mueller-Hinton Agar using National Committee for Clinical Laboratory Standard (NCCLS, 2002) guidelines [27]. The antibiotic discs (antibiotic concentration in $\mathrm{mg}$ ) used were consisted of ampicillin $(10 \mathrm{mg})$, tetracycline $(30 \mathrm{mg})$, amoxicillin (20 $\mathrm{mg})$, kanamycin (30 mg), chloramphenicol $(30 \mathrm{mg}$ ) and spectinomycin $(100 \mathrm{mg})$. Results were evaluated according to NCCLS of the reference zone diameter interpretive standards (millimeter) and minimal inhibitory concentration (MIC) breakpoints. Strains were evaluated as susceptible, intermediate and resistant. An isolate was defined as resistant if it was resistant to one or more of the antimicrobial drugs.

\section{Data analysis}

The raw data were entered and managed in Microsoft Excel work sheet; and descriptive statistic was utilized to summarize data. The prevalence was calculated for all data by dividing positive samples by total number of examined samples and multiplied by hundred. The association between the prevalence of Salmonella and associated factors (egg sample, breed and house) was assessed by Chi-square $\left(\chi^{2}\right)$. A statically significant association between variables is considered to exist if the computed p-value is less than 0.05 .

\section{Results}

\section{Prevalence}

Salmonella spp. was isolated from 11 (2.9\%) egg samples by conventional culture technique and all isolates were confirmed by biochemical test. Nine Salmonella spp. were identified from eggshells and 2 were recovered from egg content samples. Of the total egg samples examined, $3(0.8 \%), 5(1.3 \%)$ and $3(0.8 \%)$ were found positive for Salmonella in eggs collected from Bovans, Fayoumi and White leg horn breeds of layer chickens, respectively (Table 2). Among the 11 chicken egg samples positive for Salmonella, 4 (1.0\%) were collected from cage house system and $7(1.9 \%)$ were received from floor house system (Table 2).

The specific prevalence of Salmonella detected from the total of 384

\begin{tabular}{|c|c|c|c|c|}
\hline Samples & No positive & Prevalence (\%) & $\mathbf{X}^{2}$ & p-value \\
\hline Eggshells & 9 & 2.3 & 0.048 & 0.826 \\
\hline Egg contents & 2 & 0.5 & & \\
\hline Total & 11 & 2.9 & & \\
\hline
\end{tabular}

Table 1: Prevalence of Salmonella by egg samples taken $(n=384)$. 


\begin{tabular}{|c|c|c|c|c|}
\hline Source of Eggs & $\begin{array}{c}\text { No of eggs } \\
\text { examined }\end{array}$ & $\begin{array}{c}\text { No of positive } \\
(\%)\end{array}$ & $\mathbf{X}^{2}$ & p-value \\
\hline Breeds & & $3(2.9)$ & 0.183 & 0.913 \\
\hline Bovans & 105 & $5(3.8)$ & & \\
\hline Fayoumi & 132 & $3(2.0)$ & & \\
\hline White leg horn & 147 & & & \\
\hline House & & $4(2.3)$ & 0.306 & 0.580 \\
\hline Cage & 171 & $7(3.3)$ & & \\
\hline Floor & 213 & & \\
\hline
\end{tabular}

Table 2: Association between Risk Factors.

egg samples examined for both egg shell and egg content were $2.3 \%$ and $0.5 \%$, respectively (Table 1 ). Of the total egg samples examined, 9 egg shell samples found positive for Salmonella; 5 (2.3\%) positive egg shell samples were obtained from floor house and $4(2.3 \%)$ positive egg shell samples were obtained from cage house. From the total 384 egg contents examined only $2(0.5 \%)$ were positive for Salmonella. There was slightly higher prevalence of Salmonella in egg shell than egg contents. On the other hand, the prevalence of Salmonella in the two houses of the farm is presented in Table 3. The prevalence of Salmonella in floor and cage houses was $3.3 \%$ and $2.3 \%$, respectively. The result revealed that of 171 egg samples examined, 4 (2.3\%) showed the presence of Salmonella while 7 out of 213 (3.3\%) egg samples were found positive. The prevalence of Salmonella in cage house (2.3\%) was slightly less than floor house (3.3\%) in the studied farm.

Even though, there were different prevalence recorded in this study, the findings suggested that no statistically significant difference $\left(\chi^{2}=0.183, p\right.$-value $\left.=0.913\right)$ in the prevalence of Salmonella in eggs of Bovans (2.9\%), Fayoumi (3.8\%) and White leg horn (2\%) breeds of layer chickens (Table 2). Similarly, there was no significant statistical variation $\left(\chi^{2}=0.306\right.$, $p$-value $\left.=0.580\right)$ in the prevalence of Salmonella in eggs among the sources from the two-house system, $3.3 \%$ in floor house and $2.3 \%$ in cage house of the farm.

Moreover, the study has also shown the prevalence of Salmonella between those egg shells and egg contents of the total sampled eggs, $2.9 \%$ in egg shell samples (2.3) and $0.5 \%$ in egg content samples. This result also indicated that there was no statistical significant difference $\left(\chi^{2}=0.048, \mathrm{p}\right.$-value $\left.=0.826\right)$ in the prevalence of Salmonella in egg samples under classified egg shells and egg contents.

\section{Antimicrobial susceptibility}

Of the total 11 Salmonella isolates subjected to antimicrobial susceptibility test using six different antimicrobials, a total of 8 (72.7\%) Salmonella isolates were found to be resistant to two or more (multidrug) antimicrobials tested. In relation to the total Salmonella isolates tested, $72.7 \%, 72.7 \%$ and $63.6 \%$ were found highly resistant to ampicillin, tetracycline and amoxacillin, respectively, while $36.4 \%$, $27.3 \%, 18.2 \%$ and $9.0 \%$ were intermediate resistant to chloramphenicol, amoxicillin, ampicillin and kanamycin, respectively. Looking at individual antimicrobial drug, resistance to ampicillin and tetracycline was the most frequently observed, and followed by amoxacillin. In general, antimicrobial susceptibility test revealed that spectinomycin, kanamycin and chloramphenicol were the drugs indicated more active against Salmonella isolated from egg samples, while tetracycline, ampicillin and amoxacillin were less effective against Salmonella isolates.

\section{Discussion}

Eggs contaminated with micro-organisms play a significant role in poultry production pathology and in the spreading of diseases to humans [28]. The present study revealed an overall prevalence rate of $2.9 \%$ in the studied egg samples with the prevalence of Salmonella $2.3 \%$ from egg shells and $0.5 \%$ from egg contents, respectively. In this study, higher prevalence of Salmonella was obtained when compare with the prevalence reported by other studies, $0.8 \%$ from table eggs (EFSA) and $0.3 \%$ from poultry eggs in Dhaka $[29,30]$. The current finding is almost comparable with $3 \%$ prevalence observed in Belgium from egg shell and egg content samples examined in different housing system [31]. The prevalence of Salmonella in this study was however lower than $7.7 \%$ recorded in South India [32], 24.17\% prevalence in Nigeria [33], 3.84\% and 5.5\% among the chicken eggs from poultry farm and marketing in North India [34], respectively and 8\% Salmonella species isolated from chicken eggs of Dhaka city [35]. The variation in the prevalence of Salmonella in eggs may be due to lack of awareness of the status of Salmonella in chicken eggs and the unhygienic situation in the farm. Moreover, the management system in practice could also be the probable reason for the variation of the prevalence. Different authors reported that the presence of chickens of different ages in the farm, the presence of arthropod pests, wet and soiled litter in the farm [36], and the housing system and flock size could be important reasons for egg contamination with various micro-organisms. Chicken feeds and hatcheries also possible sources of Salmonella infections in the farm.

The result of this study showed a relatively higher prevalence of Salmonella in egg shells (2.3\%) than $0.5 \%$ in egg contents. However, this difference was not statistically significant $(\mathrm{p}>0.05)$. The prevalence of Salmonella in egg shell (2.3\%) in this study indicated relative agreement with $2.7 \%$ prevalence of Salmonella reported by Akhtar [37]. However, it is much lower than $10.5 \%$ prevalence reported by Loongyai et al. and $6.1 \%$ egg shell contamination [32,38]. Isolation of Salmonella from egg shell in this study may be due to contamination of eggshells at lay with faeces from intestinal carriers. De Buck et al. showed that infected birds produced the highest frequency of contaminated eggs in the first week post infection [39]. Chicken faeces, dust, litter and egg collector can also contaminate the egg shells. Smeltzer et al. indicated that eggs laid in wet, dirty nests or on the floor are more likely to be contaminated with microorganism [36]. Davies and Breslin also stated that farm environment, poor hygiene and disinfecting of materials are possible reasons of egg contamination in the farm. The findings of Salmonella prevalence in chicken egg contents was lower than the reports made by Suresh et al. [32] who reported $1.8 \%$ prevalence and also lower than Akhtar et al. who reports $8.33 \%$ prevalence [37]. The level of egg contents contamination in this study was slightly higher than the $0.017 \%$ prevalence reports (HKSAR) and no contamination of egg contents $[38,40,41]$. It is believed that the main source of egg content Salmonella contamination could be the infected ovary and/or oviduct. It is generally believed that the deposition of Salmonella inside eggs is thus most likely a consequence of reproductive tissue colonization in infected laying hens. Methner et al. also revealed that no correlation was found between the contamination of the eggshell and that of the egg contents [42]. In a study of naturally infected flocks, numerous

\begin{tabular}{|c|c|c|c|}
\hline \multirow{2}{*}{ Antimicrobials } & \multicolumn{3}{|c|}{ Number of antimicrobials tested isolates } \\
\cline { 2 - 4 } & Sensitive (\%) & Intermediate (\%) & Resistant (\%) \\
\hline Ampicillin & $1(9.1)$ & $2(18.2)$ & $8(72.7)$ \\
\hline Tetracycline & $3(27.3)$ & 0.0 & $8(72.7)$ \\
\hline Amoxicillin & $1(9.1)$ & $3(27.3)$ & $7(63.6)$ \\
\hline Kanamycin & $10(91.0)$ & $1(9.0)$ & 0.0 \\
\hline Chloramphenicol & $7(63.6)$ & $4(36.4)$ & 0.0 \\
\hline Spectinomycin & $11(100)$ & 0.0 & 0.0 \\
\hline
\end{tabular}

Table 3: Percentage of antimicrobial sensitivity test among Salmonella isolated from raw chicken eggs. 
Citation: Tessema K, Bedu H, Ejo M, Hiko A (2017) Prevalence and Antibiotic Resistance of Salmonella Species Isolated from Chicken Eggs by Standard Bacteriological Method. J Vet Sci Technol 8: 421. doi: 10.4172/2157-7579.1000421

Page 4 of 5

Salmonella serotypes, such as Salmonella enteritidis, S. typhimurium and $S$. hadar, were isolated from eggshells, whereas only S. enteritidis was isolated from egg contents [43]. Other study also reported that oneday-old chicks orally infected with $S$. pullorum produced contaminated eggs frequently during the period of sexual maturity as a consequence of reproductive tract colonization [44].

In this study, the prevalence of Salmonella is not much house dependent even though there was a slight increase in the prevalence of Salmonella from egg sample in the floor housing system (3.3\%) than cage housing system (2.3\%). The difference was not statistically significant. This finding was supported by the prevalence result of $1.8 \%$ in floor house and $1.4 \%$ in cage house [31]. The slight increase of prevalence may be because of hygienic status, air quality and confinement of birds. In addition, dust originated from feed and faeces may contain large number of microorganisms. The study also indicated that Salmonella was isolated from egg shells collected from both floor and cage house systems, whereas Salmonella was detected in egg contents sampled from only floor house system. The positive egg contents in the floor house system may be due to cross contamination of eggs at time of laying. Contamination of eggs with Salmonella was believed to occur when the organism passed from the shells into its inner contents. Spark and Board, (1985) showed that the moisture content in newly laid eggs diminishes the ability of cuticle to protect the egg contents. With so-called bed wet eggs, drops of water penetrate the cuticle, change its structure and enable micro-organisms to enter the egg contents immediately after laying. According to Humphrey increased stress could play a role to induce some changes in the chemistry of the oviduct, which might create an environment that is more susceptible for Salmonella in floor house system [45]. Occurrence of Salmonella in eggs collected from Bovans, Fayoumi, and White leg horn chicken breeds were $2.9 \%, 3.8 \%$ and $2.0 \%$, respectively. There was no statistical significant difference $(\mathrm{p}>0.05)$ in the recovery rate of Salmonella from the eggs of the three breeds of layer chickens. This is presumably due to unequal exposure to the risk factors as the breeds were housed in different house system. Slightly higher prevalence was observed in eggs collected from Fayoumi chicken breed (3.8\%). This difference might be due to Fayoumi breed was kept in the floor house system in which there is lower hygienic and high cross contamination between the flock eggs at laying than the cage house system.

Many of the isolates are resistant to multiple antimicrobial agents tested. The antimicrobial resistant recorded in this study is in consistent with $81 \%$ of tetracycline and $73 \%$ of ampicillin reported by Miko et al. [13]. High level of antimicrobial resistant Salmonella occurred in this study is probably an indication of their frequent usage both in the animal and public health sectors. The finding of this study shows slightly lower resistant than the study reported $93.1 \%$ for tetracycline and amoxicillin in Nigeria from Salmonella isolates in chicken eggs [33]. Alemayehu et al. also showed $52 \%$ of the Salmonella isolates from beef were resistant to at least three antibiotics from beef in Ethiopia, Salmonella isolates sensitivity to spectinomycin (100\%) and kanamycin (91\%) indicates the most active antimicrobial against Salmonella in poultry farms, which agrees with the report of an overall $2.9 \%$ spectinomycin resistance for Salmonella isolates from swine slaughtered in Addis Ababa abattoir $[9,46]$. Since the 1990s the frequency of antimicrobial drug resistance in zoonotic Salmonella and number of drugs to which the strains are resistant have increased, primarily as a consequence of antimicrobial use in food production may be associated with adverse consequences in several ways including treatment failures $[47,48]$.

In the present study, the antimicrobial-resistant strains were found up to $72 \%$ of the total 11 Salmonella isolates tested, which is greater than those in previous studies of nonclinical isolates from dairy cattle. Most of these isolates are resistant to multiple antimicrobial agents tested, particularly for ampicillin, amoxicillin and tetracycline. Resistance to ampicillin, amoxicillin and tetracycline were widespread. This may be due to the widespread use of antibiotics included in feeds and in chickens. When compared to the resistant Salmonella isolates obtained from chickens in other studies, the prevalence of antimicrobial resistance in this study is much lower. $92 \%$ resistant to tetracycline Salmonella isolated from meat products in Ireland. The possible explanation could be the increased antimicrobial use in poultry farm and an association between resistance and virulence factors. Resistance rates to ampicillin, chloramphenicol, gentamycin, and trimethoprim of the isolates in the present study were low. However, it is important to note that these antibiotics are commonly used in veterinary medicine, and infections with these resistant Salmonella isolates could lower the efficiency of antibiotic treatment.

\section{References}

1. FAO (1999) Prospects for the future: emerging problems- chemical/biological Conference on International Food Trade Beyond 2000: Science-based Decision, Harmonization, Equivalence and Mutual Recognition Melbourne, Australia, pp: 1-20.

2. Gomez TM, Motarjemi Y, Miyagawa S, Kaferstein FK, Stohr K (1997) Foodborne salmonellosis. World Health Stat 50: 81-89.

3. Velusamy V, Arshak K, Korostynska O, Oliwa K, Adley C (2010) An overview of foodborne pathogen detection: In the perspective of biosensors. Biotechnol Adv 28: 232-254

4. Carrasco E, Morales-Rueda A, García-Gimeno RM (2012) Crosscontamination and recontamination by Salmonella in foods: a review. Food Res International 45: 545-556.

5. Finstad S, O'Bryan CA, Marcy JA, Crandall PG, Ricke SC (2012) Salmonella and broiler processing in the United States: Relationship to foodborne salmonellosis. Food Res International. 45: 789-794.

6. D'Aoust JY (1997) Salmonella Species. In: Doyle MP, Beuchat LR, Montville TJ (eds.). Food Microbiology Fundamentals and Frontiers, ASM Press, Washington DC, USA, pp: 129-158.

7. Luber $P$ (2009) Cross-contamination versus undercooking of poultry meat or eggs-which risks need to be managed first? Int J Food Microbiol. 134: 21-28.

8. Mead G, Lammerding AM, Cox N, Doyle MP, Humbert F, et al. (2010) Scientific and technical factors affecting the setting of Salmonella criteria for raw poultry: Global perspective. J Food Prot 73: 1566-1590.

9. Ejeta G, Molla B, Alemayehu D, Muckle A (2004) Salmonella serotypes isolated from minced meat beef, mutton and pork in Addis Ababa, Ethiopia. Revue Med Vet. 155: 547-551.

10. Stevens A, Kabore Y, Perrier-Gros-Claude JD, Millemann Y, Brisabois A, et al (2006) Prevalence and antibiotic-resistance of Salmonella isolated from bee sampled from the slaughterhouse and from retailers in Dakar (Senegal). Int $\mathrm{J}$ Food Microbiol 110: 178-186.

11. Bell C, Kyriakides A (2002) Salmonella: A Practical Approach to the Organism and Its Control in Foods. Wiley-Blackwell, Oxford.

12. Zhao S, White DG, Friedman SL, Glenn A, Blickenstaff $K$, et al. (2008) Antimicrobial resistance in Salmonella entericaserovar Heidelberg isolates from retail meats, including poultry, from 2002 to 2006. Appl Environ Microbiol. 74: 6656-6662.

13. Miko A, Pries K, Schroeter A, Helmuth $R$ (2005) Molecular mechanisms of resistance in multidrug-resistant serovars of Salmonella enterica isolated from foods in Germany. J Anti Microb Chemother 56: 1025-1033.

14. Van Duijkeren E, Wannet WJB, Houwers DJ, VanPelt W (2001) Serotype and phage type Distribution of Salmonella strains Isolated from Humans, Cattle, Pigs, and Chickens in the Netherlands from 1984 to 2001. J Clin Microbiol 40: 3980-3985.

15. Humphrey TJ (1991) Infection by Salmonella Enteritidis in laying chickens y gallinas. Campylobalterolomestilas, Mexico. pp: 20-26. 
Citation: Tessema K, Bedu H, Ejo M, Hiko A (2017) Prevalence and Antibiotic Resistance of Salmonella Species Isolated from Chicken Eggs by Standard Bacteriological Method. J Vet Sci Technol 8: 421. doi: 10.4172/2157-7579.1000421

Page 5 of 5

16. Bichler LA, Nagaraja KV, Halvorson DA (1996) Salmonella enteritidis in eggs, cloacal swab specimens and internal organs of experimentally infected White Leghorn chickens. J Vet Res. 57: 489-495.

17. Gast RK, Guraya RJ, Guard-Bouldin PS, Holt, Moore RW (2007) Colonization of specific regions of the reproductive tract and deposition at different locations inside eggs laid by hens infected with Salmonella enteritidis or Salmonella heidelberg. Avian Dis. 51: 40-44.

18. Gantois I, Ducatelle R, Pasmans F, Haesebrouck F, Gast R, et al. (2009) Mechanisms of egg contamination bySalmonellaEnteritidis. FEMS Microbiol Rev. 33: 718-738.

19. Barrow PA, Lovell MA (1991) Experimental infection of egg-laying hens with Salmonella Enteritidis phage type 4. Avian Pathol 20: 335-348.

20. Molla B, Mesfin A (2003) A survey of Salmonella contamination in chicken carcass and giblets in central Ethiopia. Revue MédVét. 154: 267-270.

21. McEwen SA, Fedorka-Cray PJ (2002) Antimicrobial use and resistance in animals. Clin Infect Dis. 34: S93-S106.

22. Vidaver AK (2002) Uses of antimicrobials in plant agriculture. Antimicrob. Plant Agric. 34: S107-S110.

23. Wise R, Soulsby EJ (2002) Antibiotic resistance-an evolving problem. Vet Rec. 151: 371-372.

24. Jay JM (2000) Foodborne gastroenteritis caused by Salmonella and Shigella. In: Modern Food Microbiology. 6th edn. pp: 511-528.

25. Thrusfield M (2005) Veterinary Epidemiology. 3rd edn. UK: Blackwell Science, p: 233.

26. ISO (1998) Microbiology of Food and Animal Feeding Stuff-horizontal Method for the Detection of Salmonella, ISO 6579:2002, Geneva.

27. NCCLS (2002) Performance Standards for Antimicrobial Disk and Dilution Susceptibility Tests for Bacteria Isolated from Animals: Approved Standard. 3rd edn. NCCLS Document M31-A2. NCCLS, Wayne, PA, USA.

28. Hassan JO, Curtiss R (1997) Efficacy of a live avirulent Salmonella typhimurium vaccine in preventing colonization and invasion of laying hens by Salmonella typhimurium and Salmonella enteritidis. Avian Dis. 41: 783-791.

29. EFSA (2009) Special Measures to Reduce the Risk for Consumers through Salmonella in Table Eggs - e.g. cooling of table eggs. The EFSA J 957: 2-7.

30. Begum K, Reza TA, Haque M, Hossain A, Hussar FMK, et al. (2010) Isolate Identification and Antibiotic Resistance Patterns of Salmonella Species from Chicken Eggs, Intestine and Environmental Samples. Bangladesh, Pharmaceutical Journal. 13: 0301-4606.

31. Devylder J, De Wulf J, Van Hoorebeke S, Pasmans F, Haesebrouck, et al. (2011) Horizontal transmission of Salmonella enteritidis in groups of experimentally infected laying hens housed in different housing systems. Poultry Sci. 90: 1-6.

32. Suresh T, Hatha AAM, Sreenivasan D, Sangaatha N, Lashmanaperumalsamy P (2006) Prevalence and Antimicrobial Resistance of Salmonella enteritidis and other Salmonellas in the Eggs and Egg-storing Trays from Retails Markets of Coimbatore, South India. Food Microbiol. 23: 294-299.
33. Ekundayo EU, Ezeake JC (2011) Prevalence and Antibiotic Sensitivity Profile of Salmonella Species in Eggs from Poultry Farms in Umudike, Abia State. J Animal Vet Adv 10: 206-209.

34. Singh S, Yadav AS, Singh SM, Bharti P (2010) Prevalence of Salmonella in Chicken Eggs Collected from Poultry Farms and Marketing Channels and Antimicrobial Resistance. Food Res International. 43: 2027-2030.

35. Ahmed MM, Rahman MM, Mahbub KR, Wahiduzzaman (2010) Characterization of Antibiotic Resistant Salmonella Species Isolated from Chicken Eggs of Dhaka City. J Scientific Res 3: 191-196.

36. Smeltzer T, Orange K, Peel B, Runge G (1979) Bacterial Penetration in Floor and Nest Box Eggs from Meat and Layer Birds. Aust Vet J. 55: 592-593.

37. Akhtar F (2008) Epidemiology and Immunoprophylaxis of Salmonella Enteritidis in Laying Hens in relation to Zoonosis. MSc Thesis, Department of microbiology, University of Agriculture, Faisalabd 12-14.

38. Loongyai, Kiettisak P, Kangsukul N, Noppha R (2010) Detection of Salmonella in Eggs Shell and Egg Contents from Different Housing Systems for Laying Hens. World Academy of Science, Engineering and Technology 4: 232-234.

39. De Buck J, Van Immerseel F, Haesebrouck F, Ducatelle R (2004) Colonization of the Chicken Reproductive tract and egg Contamination by Salmonella. J Appl Microbiol. 97: 233-245.

40. HKSAR (2004) Salmonella in Eggs and Egg Products. Food and environmental Hygiene Department, Queensway, Hong Kong. Pp: 1-20.

41. Sasaki Y, Sujiyama Y, Asai T, Noda Y, Katayama S, et al. (2011) Salmonella Prevalence in Commercial Raw Shell Eggs in Japan: A survey. Epidemio Infect. 139: 1060-1064.

42. Methner U, Al-Shabibi S, Meyer H (1995) Experimental oral infection of Specific Pathogen-Free laying Hens and Cocks with Salmonella Enteritidis strains. Zoonoses Public health 42: 459-469.

43. Humphrey TJ, Whitehead A, Gawer A, Henley A, Rowe B (1991) Numbers of Salmonella enteritidis in the Contents of Naturally Contaminated Hen's Eggs. Epidemiol Infect. 106: 489-496.

44. Wigley P, Berchieri A, Page KL, Smith MH, Barrow PA (2001) Salmonella entericaserovarPullorum persists in Splenic Macrophages and in the Reproductive Tract during Persistent, Disease-Free Carriage in Chickens. Infect Immun. 69: 7873-7879.

45. Humphrey T (2004) Salmonella, Stress Response and Food Safety. Nature Reviews Microbiol. 2: 504-509.

46. Aragaw K (2005) Salmonella in Apparently Healthy Slaughtered Swine in Addis Ababa, Ethiopia.MSc thesis Addis Ababa University, Faculty of Veterinary Medicine, DebreZeit, Ethiopia.

47. Helms M, Vastrup P, Gerner-Smidt, Molbak K (2003) Short and long term mortality associated with foodborne bacterial gastrointestinal infections: registry based study. BMJ. 326: 1-5.

48. Beran H (1994) Hand book of Zoonoses Section A: bacterial, rickettsial, chlamydial and mycotic. USA CRC Press, pp: 289-300. 